\title{
METHODS OF PRODUCTIVITY IMPROVEMENT: A LITERATURE REVIEW
}

\author{
Anukriti Sahni ${ }^{1}$ \\ ${ }^{1}$ Industrial Engineering, Shri Ramdeobaba College of Engineering and Management, Nagpur, India
}

\begin{abstract}
Productivity Improvement is one of the most important factors for an organization to survive in this growing competition. Globalization has given rise to new standards for products and the demands of the customers have to be met keeping the appropriate standards for quality, variety and other factors that have become mandatory for the organization to have an edge over the others. A literature review has hence been carried on the importance of productivity improvement in an organization, the various methods adopted for the purpose of the improvement. The various methods have been discussed in detail with their outcomes on the productivity of various organizations
\end{abstract}

\section{Keywords - KANBAN, Work Study, Setup Reduction, Productivity, Lean Manufacturing, 5 S}

\section{INTRODUCTION}

As stated by Kulkarni et al. 2014, productivity is the ratio of output and the input. i.e. Productivity = Output/ Input (Verma et al. 2015). According to Mishra 2013, productivity improvement focusses on: Doing the "right thingse (i.e. know "what" to produce and distribute) by continuously reviewing and identifying changing customer and societal needs. Doing "things right"e (i.e. know "how" to prduce and distribute) by constantly improving production and distribution processes to produce and deliver the goods and services in the most efficient way. The rate at which a company produces goods or services in relation to the amount of materials and number of employees needed (Verma et al. 2015). Input: Material, Machine, Man Hours, Methods, Land. Output: Parts \& product, Services, Wastage of any type, Pollutants of any type (Verma et al. 2015) The paper focuses on the researches which are based on improvement in productivity using various methods such as time and motion study, use of KANBAN system, use of a productivity improvement model, redesigning equipments, methods or techniques, reduction of set up time, lean manufacturing, 5S implementation etc.

A few of these are explained as follows:

Setups performed in-line-on the tool in lieu of running product take away from production time and may be classified as waste so the setup procedures should be analyzed to see if they can be done in parallel, off line, to allow production to continue (Kumar 2013).

Kulkarni et al. 2014, clearly stated the reson for which set up time should be reduced by answering the following question;

Why Setup Reduction?

"Equipment and the operator are occupied but there is NO output"
Setup time reduction improves the equipment availability, increasing the total capacity \& results in:

- Better utilization of operator's time.

- Better utilization of resources \& capital cost.

- Reduced capital investment. (Kulkarni et al. 2014)

As stated by Verma et al. 2015, Time Study is a work Measurement technique which is involved to calculate the time of the operation in an assembly line with the help of an instrument (stopwatch) and Motion Study is a technique of analyzing the body motions employed in doing a task in order to eliminate or reduce ineffective movements and facilitates effective movements.

The benefits as stated in the study by Marri and Shaikh, 2012 who considered time and motion study as the most effective measure of productivity improvement are as follows:

- It helps, increase production \& productivity

- It can reduce indirect and direct costs

- It offers improvements in working conditions

- It helps in reducing the fatigue or danger

- It ensures proper utilization of costs \& controls (Marri and Shaikh, 2012)

Kulkarni et al.2014, explained 5S in the following 5 Steps- Sort: Completely Sort out \& classify that which item is required and/or not required in the work area.

- Set in Order: Arrange items in required order that are important so that they are ready to find \& easy to use.

- Shine: Clean the work area, tools, machine \& equipments on a continuous basis in order to identify

defects\& maintain standards.

- Standardize: Ensure standard \& uniform procedures and methods throughout the operation to promote changeover.

- Sustain: Stay to the regulations to maintain the standard \& continue to improve every day. 


\section{METHODS}

An easy way to comply with the conference paper formatting requirements is to use this document as a template and simply type your text into it.

The various methods used for productivity improvement are as follows:

\subsection{Kanban System}

A KANBAN system has been applied as a measure of productivity improvement by Shrivastava et al., 2015 in a Tractor manufacturing company for an assembly plant for a pilot batch of 88 different types of components procured from the vendor. It produces 3000-3500 tractors per month i.e. daily capacity of 140 tractors.

A KANBAN system when stated with an example of three bins at various locations. The first bin being on the floor of the factory in the vicinity of the operator in charge, the second one being in the storage department where a bin full of the required parts is available and the third being with the supplier/vendor. All the three bins will have removable card. These cards contain the details of the respective products such as the card number, the vendor details etc. The system as explained by Shrivastava et al., 2015 works in the following manner:

When the products in the bin with the operator on the factory floor are consumed, the bin along with its KANBAN card is returned to the storage department. This department has a bin full of the product with it, with its KANBAN card. The storage department then replaces the empty bin from the floor with the full bin it has. Now, the department sends this empty bin with its respective KANBAN card to the supplier/vendor. The supplier/ vendor now sends the bin full of the required product with its respective KANBAN card to the store/ storage department and the vendor retains the empty bin.

The specification on the KANBAN card to be followed in the procedure as stated by Shrivastava et al., 2015 are as follows:

The supplier has to mention the card number of the material that was dispatched by him. This number on invoice has to be checked with the free KANBAN card available. The quantity on invoice should match with the card quantity. The Container type specified on the card should only be used to store the components. The card should be attached to the container and both should move together till container becomes empty. The material should be stored on the location specified on card only (Shrivastava et al., 2015).

This is one such process where in there in no scope of shortage of products. This system ensures that there will be no shortage or no oversupply of products at the floor or the storage department as at a time there is only one extra supply of a bin full of the products.
- An average inventory reduction of $43.77 \%$ was obtained

- Pallets, containers and factory space were utilized in the most optimum manner

- Quality was improved as the system had a shorter queue

- Waste in all forms was eliminated, and turnover ratio of capital would increase.

As a result of these the productivity of the company will be improved.

\subsection{Set Up Reduction}

A study conducted by Kumar, 2012 stated that Set up Reduction cost is the perfect way of ensuring productivity improvement of CNC set up in a manufacturing company. Kumar, 2012 carried out a study in a packaging firm and stated 3 benefits of reducing the set up time, which include: additional available time for production which can be used:

- to boost capacity i.e. to produce more

- $\quad$ to produce wider range of products i.e. producing small batches with more set-up frequency

- reduction in production cost

Kumar, 2012 stated the phases of setup reduction and depicted it in a graphical manner. These phasers include (Kumar, 2012):

\section{- Maintenance, organization and housekeeping \\ - Internal elements to external \\ - Improve elements \\ - Eliminate adjustments}

These are shown in the figure 1.

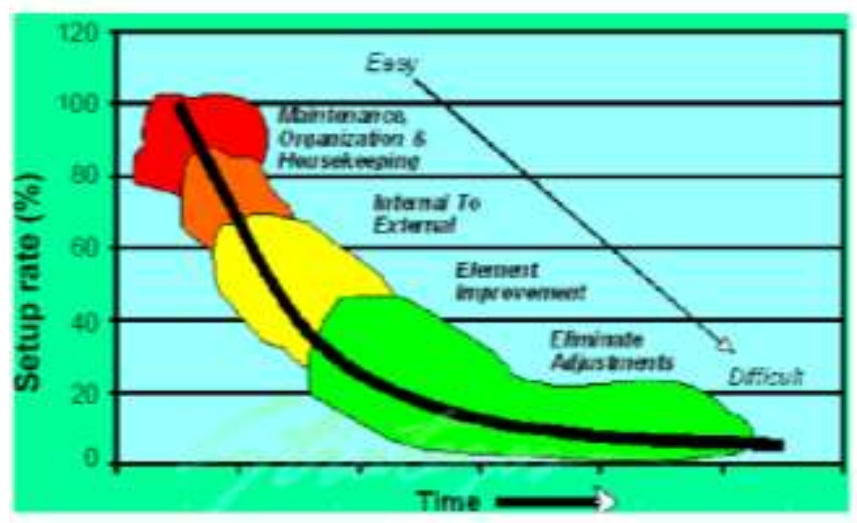

Fig 1: Phases of setup reduction (Kumar, 2012)

The results were as follows: Waste time was reduced to a great extent and more time was available for only machining; hence production rate was increased.

The following graphs indicate down time was highest in the month of December 2008 (149.25 h) with a reduction in June 2008 (113.75) which was further reduced in May 2009 (59.75h).

These are represented in the figure 2 and figure 3.

According to Shrivastava et al., 2015 the results are: 


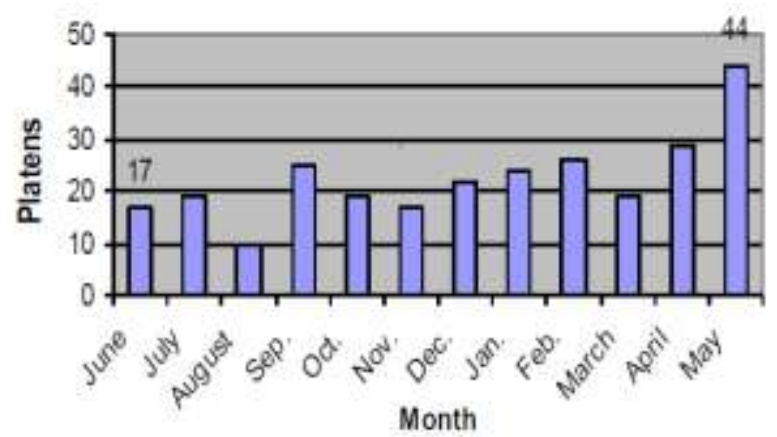

Fig 2: Platens produced on CNC Machine from June 2008 to May 2009 (Kumar, 2012)

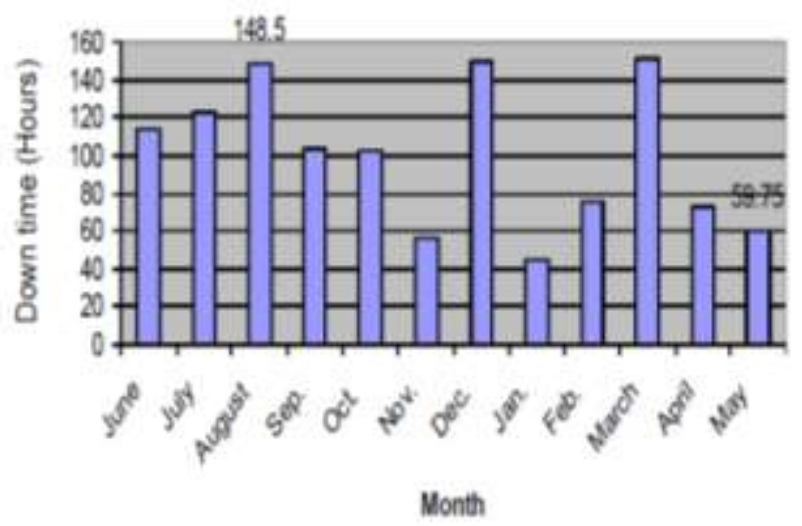

Fig 3: Downtime from CNC Machine from June 2008 to May 2009 (Kumar, 2012)

\subsection{S, Time Study \& Motion Study}

Verma et al., 2015 conducted a study indicating that productivity improvement can be achieved using motion study and time study. The study was carried out on two units -ADHITYA AUTOMOTIVES APPPLICATION PVT LTD and TATA MOTORS.

The problems and suggestions as suggested by Verma et al., 2015 are as follows:

\section{At Tata Motors (Verma et al., 2015):}

1. During the accelerator pedal assembly, the worker had to travel more to collect the parts.

2. 5S was not being used on the sub-assembly table.

Suggestion: An accelerator pedal sub assembly trolley was made to reduce the motion of worker and $5 \mathrm{~S}$ was maintained on the table.

1. Time required for the assembly of the accelerator pedal was more because of Non Varying Activities

Suggestion: Using a trolley reduced the motion of worker and fatigue was reduced

The Non Value Added and Value Added time was identified and the outcome was measured which is represented in the table 1(Verma et al., 2015).

Table 1: Results of reduction in time and motion before and after the using the trolley (Verma et al., 2015) BEFORE AFTER

\begin{tabular}{|l|l|l|}
\hline Motion Reduction & $73.2 \mathrm{~m}$ & $32 \mathrm{~m}$ \\
\hline $\begin{array}{l}\text { Time Reduction } \\
\text { Space Reduction }\end{array}$ & $\begin{array}{l}\text { 124 Sec } \\
\text { Subassembly table was stopped to be } \\
\text { used }\end{array}$ & $\begin{array}{l}51 \mathrm{Sec} \\
\text { Introduction of movable trolley reduced } \\
\text { space }\end{array}$ \\
\hline Fatigue Reduction & High Fatigue due to high movement & $\begin{array}{l}\text { Fatigue reduced due to movement } \\
\text { reduction }\end{array}$ \\
\hline $\begin{array}{l}\text { Improved Ergonomics } \\
\text { Improved Quality }\end{array}$ & Worker had to bend to pick up parts & Part kept at the level of worker \\
\hline
\end{tabular}

Percentage decrease in time $=(124-51) / 124 \times 100=58.3 \%$

Percentage decrease in the motion of the worker $=(73.2-32) / 73.2 \times 100=56.3 \%$

At Aaditya Automotives Applications Pvt Ltd (Verma et al., 2015)

1. The table was used for side board tack welding; it was only for 12 cubic meter tipper model.

2. Workers were having a difficulty in placing the side board on the table too.

Suggestion: A new fixture was designed to do tack welding for $12,10,14$, and heavy duty vehicles with different.

1. It consumes more time for side board tack welding table as there were no holding devices.
Suggestion: According to the design of new fixture the time required for the side board tack welding was reduced with a huge difference.

Time reduction: BEFORE 111 min \&After: 45min

Hence percentage reduction in time is given as $=(111-$ $45) / 111 \times 100=59.45 \%$ IT,

This shows that up to $\mathbf{6 0 \%}$ time is reduced with the advancement in fixture which increased the production of Tippers from $\mathbf{3 0}$ to $\mathbf{7 5}$ Tippers in the month. (Verma et al., 2015) 


\subsection{S \& Systematic Layout Planning}

A study was conducted by Singh et al. 2015 in a company which manufactures different mechanical components (100gm to $200 \mathrm{~kg}$ weight) by using casting. The company also involved in machining of components produced by casting.

The problem as identified by Singh et al. 2015 in the company was:

- less productivity due to ineffective utilization of plant layout,

- less space for storage,

- material handling problems etc.

Objective of the study conducted by Singh et al., 2015was to improve productivity in the best and effective manner without compromising quality of products.
To met the objective Singh et al. 2015 had to do the following:

- improve the utilization of plant area

- Change in plant layout,

- Change in process layout

- Applying work and motion study

- Reducing non-productive time

- Applying ergonomics for various working position.

The types of problems occurred in the company during the study by Singh et al. 2015 were:

- Improper Plant Layout

- Material Flow and Movement

- Storage Problem

- Material Handling Problem

- Manual Process

As a result Singh et al. 2015 designed a new plant layout using Systematic Layout Planning (SLP). The result is as shown in the table 2.

Table 2: The comparison of distance travelled by present and proposed layout (Singh et al., 2015)

\begin{tabular}{|c|c|c|}
\hline Components & $\begin{array}{c}\text { Distance travelled by components in } \\
\text { present layout (m) }\end{array}$ & $\begin{array}{c}\text { Distance travelled by components in } \\
\text { proposed layout (m) }\end{array}$ \\
\hline Crank case & 319.73 & 143 \\
\hline Crank shaft & 105.6 & 82 \\
\hline Connecting rod & 66.3 & 59 \\
\hline Flywhel & 172 & 67 \\
\hline Total & 663.63 & 351 \\
\hline
\end{tabular}

This proposed layout had the following benefits associated with it as proposed by Singh et al., 2015:

- Reduction in production time,

- Reduction in number of manual processes

- Reduction in back flow of materials

- Reduction in storage problem

- Reduction in material handling problem

- Reduction in material movement

Also, Singh et al. 2015 used the 5s technique.

By using the 5S technique the following were achieved (Singh et al. 2015):

- Clear visibility of problem

- Improved safety

- Reduction in waste

- Improved morale of employee

- Increased sense of ownership of the workspace

- Improved productivity, quality, maintenance

- Shorter lead times and a better impression on customers.

Material handling and improper material movements are avoided by using pallet trucks (Singh et al. 2015).

Thus, the travel distance and the time taken in the existing and new plant layout are as follows (Singh et al. 2015):
Existing Plant layout:

Travel distance $=125.13 \mathrm{~m}$

Time taken $=391.75 \mathrm{~min}$

Total travel distance $=188.5311 \mathrm{~m}$

New Plant Layout:

Travel Distance $=67.9 \mathrm{~m}$

Time Taken $=389.53 \mathrm{~min}$

Total travel distance $=92.7662 \mathrm{~m}$

Thus (Singh et al., 2015),

Reduction in distance $=57.23 \mathrm{~m}$

Reduction in time $=2.22 \mathrm{~min}$

Reduction in total travel distance $=95.7649 \mathrm{~m}$ (i.e. reduction by $49.2047 \%$ )

\subsection{Time Study}

Mishra 2015 carried out a study in an Automobile industry in order to improve the productivity.

Problems as identified by Mishra 2015 which were hampering the productivity were:

Unwanted activities were being carried out which were consuming much extra time, extra efforts, unwanted costs and increased level of fatigue among workers. 
Thus, the objective of the study by Mishra 2015 was to study the procedures involved in the work being carried out in the production department and improving the productivity by identifying and reducing the time consuming processes and eliminating them.

The research methodology included: Systematic observation, flow process and stop watch time study (Mishra 2015).

Software used for the purpose of new model development and model testing was Pro-E model.

The conclusion of the study conducted by Mishra 2015 was: Improvement of work process was executed by eliminating and combining of work process, which reduced production time, number of processes and space utilization (Mishra 2015).

The improvement as suggested by Mishra 2015 was in respect to using less complicated, lighter tools and tools that are easy to use. The details of the problems and suggestions are as follows (Mishra 2015):

- Initially finished components were kept directly on the pallet

\section{Suggestion:}

They can be kept on a trolley to transport the component to the next department (i.e. the paint shop)

- Finished component from "injection molding machine to the pallet" was taking unnecessary operation and increasing worker's fatigue and the cost of the production because there was less component delivery, in a day, from production to paint shop department.

\section{Suggestion:}

Removing pallet to keep the component directly on the trolley to save time and reduce the worker's fatigue so that the worker could produce more components.

The outcome of the study is given in table 3 :

Table 3: Outcome before and After implementation of the suggestions (Mishra 2015)

\begin{tabular}{|l|l|l|l|}
\hline S.N. & Detail & $\begin{array}{l}\text { Before } \\
\text { Implementation }\end{array}$ & $\begin{array}{l}\text { After } \\
\text { implementation }\end{array}$ \\
\hline 1 & $\begin{array}{l}\text { No of } \\
\text { product } \\
\text { produced } \\
\text { in week }\end{array}$ & $80 \times 7=560$ & $84 \times 7=588$ \\
\hline 2 & $\begin{array}{l}\text { No of } \\
\text { product } \\
\text { produced } \\
\text { in month }\end{array}$ & $80 \times 30=2400$ & $84 \times 30=2520$ \\
\hline 3 & $\begin{array}{l}\text { No of } \\
\text { product } \\
\text { produced } \\
\text { in year }\end{array}$ & $\begin{array}{l}2400 \times 12= \\
28800\end{array}$ & $\begin{array}{l}2520 \times 12= \\
30240\end{array}$ \\
\hline 4 & $\begin{array}{l}\text { Profit per } \\
\text { year }\end{array}$ & $\begin{array}{l}28800 \times 450= \\
12960000\end{array}$ & $\begin{array}{l}30240 \times 450= \\
1360800\end{array}$ \\
\hline
\end{tabular}

\subsection{Productivity Improvement Model}

A study conducted by Al-Shayeaet al. 2011, was based on improving productivity using a productivity improvement model. A model was developed that would select the best technique to perform significant process operations among proper candidate techniques in order to improve the productivity while minimizing these operation's risk and fatigue, cost and time associated with implementation of that particular technique (Al-Shayea et al. 2011).

Formulation of the Productivity Improvement Model includes the following (Al-Shayea et al. 2011):

INDICES (Al-Shayea et al. 2011):

$i$ Operation type $\mathrm{i}=1 \ldots \mathrm{n}$

$j$ Technique type $\mathrm{j}=1 \ldots . . \mathrm{n}$

where:

$n$ Number of operations

$m$ Number of candidate techniques

PARAMETERS (Al-Shayea et al. 2011):

fij Fund requirement for technique j, at operation i

SPi Standard productivity at operation i, (for the current technique)

SPji Standard productivity after using technique $\mathrm{j}$, at operation i

RAi Relaxation allowance at operationi(for the current technique)

RAji Relaxation allowance after using technique $\mathrm{j}$, at operationi

RMi Risk measured at operation i(total severity points for the current technique)

RMji Risk measured (total severity points) after using technique $\mathrm{j}$ at operationi

aji Annual savings after using technique $\mathrm{j}$, at operationi

ASi Minimum annual savings for operationi

AST Minimum annual savings for the whole operations at the workplace

$\mathrm{Ai}$ Maximum available funds (or maximum budget) for operation, $i$

AT Maximum available funds (or maximum budget) for the whole operations at the workplace

bji Payback period after using technique, at operation $\mathrm{i}$

Bi Maximum allowable payback period as per organization policy for the whole operations at the workplace B

mji Time required to install technique $\mathrm{j}$, at operationi

$\mathrm{Mi} \quad$ Maximum allowable installation time at operationi

MT Maximum allowable installation time for all selected techniques

VARIABLES (Al-Shayea et al. 2011)

xji Technique $\mathrm{j}$ that is used to improve productivity at operation $\mathrm{i}$

MODEL OBJECTIVE FUNCTION (Al-Shayea et al. 2011)

Thus,

Increase in Profit $/$ year $=1360800-12960000=$ Rs. 648000 


$$
\operatorname{Max} \sum_{i=1}^{n} \sum_{j=1}^{m} S P_{j, i} x_{j, i} \quad i=1, \cdots, n \text { and } j=1, \cdots, m
$$

\section{MODEL CONSTRAINTS (Al-Shayea et al. 2011):}

The model constraints represent the conditions that should be satisfied in order to achieve the model aim.

The constraints as stated by Al-Shayea et al. 2011 are as follows:

The first constraint deals with the fund requirements:

$$
\sum_{i=1}^{n} \sum_{j=1}^{m} f_{j, i} x_{j, i} \leq A_{T} \quad i=1, \cdots, n \text { and } j=1, \cdots, m
$$

The second constraint deals with the installation time:

$$
\sum_{i=1}^{n} \sum_{j=1}^{m} m_{j, i} x_{j, i} \leq M_{T} \quad i=1, \cdots, n \text { and } j=1, \cdots, m
$$

The third, fourth and fifth constraints deal with verifying that relaxation allowance, the total productivity gains and the risk measured:

$$
\begin{aligned}
& \sum_{j=1}^{m} R A_{j, i} x_{j, i}<R A_{i} \quad i=1, \cdots, n \\
& \sum_{j=1}^{m} S P_{j, i} x_{j, i}>S P_{i} \quad i=1, \cdots, n \\
& \sum_{j=1}^{m} R M_{j, i} x_{j, i}<R M_{i} \quad i=1, \cdots, n
\end{aligned}
$$

The sixth and seventh constraints deal with the average annual savings and the average payback period:

$$
\begin{gathered}
\sum_{i=1}^{n} \sum_{j=1}^{m} a_{j, i} x_{j, i}>A S_{T} \quad i=1, \cdots, n \text { and } j=1, \cdots, m \\
\sum_{i=1}^{n} \sum_{j=1}^{m} b_{j, i} x_{j, i} \leq B_{T} \quad i=1, \cdots, n \text { and } j=1, \cdots, m
\end{gathered}
$$

The last two constraints are to verify that only one technique is selected:

$$
\begin{gathered}
\sum_{j=1}^{m} x_{j, i}=1 \quad i=1, \cdots, n \\
x_{j, i}=0,1 \quad i=1, \cdots, n \text { and } j=1, \cdots, m
\end{gathered}
$$

Problem identified by Al-Shayea et al. 2011 was that the administration of Al-Babtain tower factory looks for increasing the factory productivity and the workers were worried about the increase in the injuries.
The PIM model was used to select the best techniques for performing operations to increase the productivity without increasing risks levels, fatigue, cost and time associated with the implementation of these techniques.

The most problematic operations at the factory were two drilling operations, operations 13 and 14. The techniques suggested were (Al-Shayea et al. 2011):

- Rebuilding old machines in order to improve

- Purchasing new drilling machines

- Replacing those machines by several hand tools

Results as given by Al-Shayea et al. 2011 were:

According to the model, the best technique was rebuilding the old drilling machines.

- The standard productivity for operations 13 and 14 increased from 34 and 70 respectively to 35 and 73.

- The risk levels decreased by approximately 35\% for operation 13 and $43 \%$ for operation 14 .

- Cost of rebuilding the two machines is Rs. 751,000 which is less than the maximum allowable fund for both operations which is Rs. 775,000

- Relaxation allowance percentage decreased from $33 \%$ to $16 \%$ and $14 \%$ for operations 13 and 14 , respectively

- The severity points were also dropped from 49 to 32 and 28 for operation 13 and 14, respectively i.e. the risk levels of both operations were reduced

- The technique has annual savings of Rs. 1.5 million and Rs. 0.15 million for operation 13 and 14 , respectively

The model was thus proved to be able to select the best technique and serve as a decision tool in productivity improvement.

\subsection{Lean Manufacturing \& Work Study}

As statetd by Kulkarni et al. 2014, Lean Manufacturing reduces the operation time of processes, increases maneuverability, and improve the corresponding attributes. It optimizes customer significance, minimizes wastes, thereby achieving manufacturing excellence through the creation of more value with fewer or no capital investments. The various tools of Lean Manufacturing are given in figure 4.

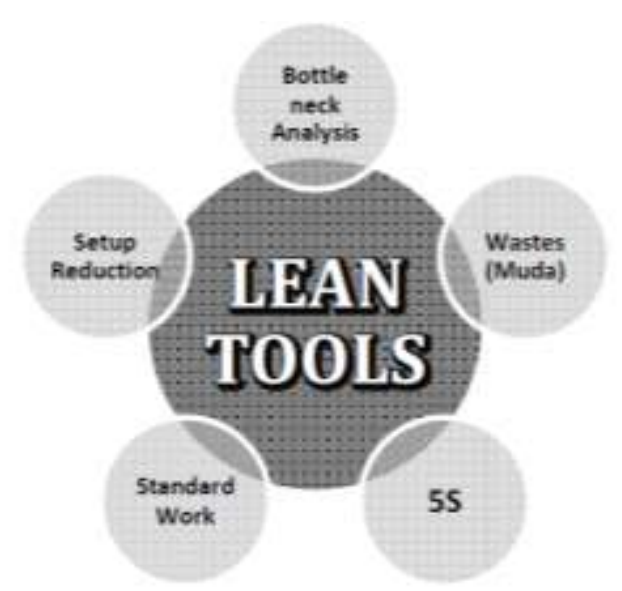

Fig 4: Lean tools (Kulkarni et al. 2014) 
Work study has been explained in brief in figure 5 .

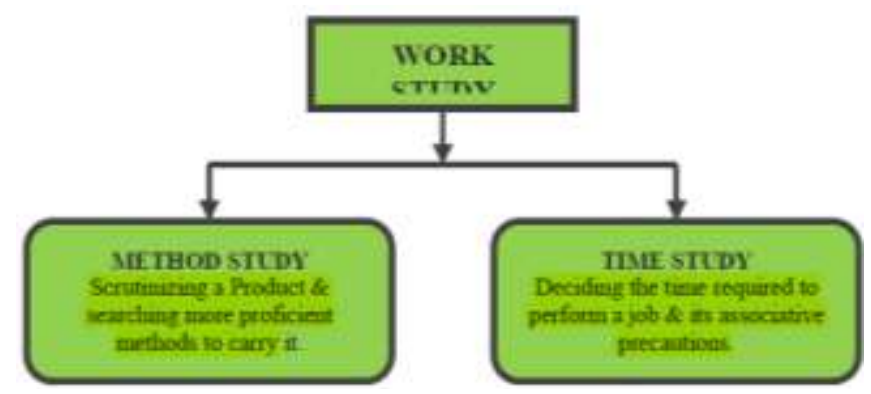

Fig 5: Work Study Methods (Kulkarni et al. 2014)

Kulkarni et al. 2014, carried out an in depth study based on work study and lean manufacturing and came to a conclusion that the two when well combined and used, will be the universal solution for any type of industry having any sort of problem regarding the productivity. If implemented in proper order, $100 \%$ positive results are assured (Kulkarni et al. 2014).

\section{CONCLUSION}

All of the above methods have proved to be able to improve productivity effectively if they are properly implemented.

\section{REFERENCES}

[1]. Adel Al-Shayea A, El-Tamimi A, Al-Saleh1 K, AlYami K., "Productivity Improvement Model without Increasing Operation's Risk and Fatigue", Scientific Research, Engineering, vol. 3, pp. 1124-1131, Nov. 2011.

[2]. Kulkarni P. P., Kshire S. S., Chandratre K. V., "Productivity Improvement Through Lean Deployment \& Work Study Methods", International Journal of Research in Engineering and Technology, vol. 03, Issue 02, Feb. 2014.

[3]. Kumar P. C., "Set up Reduction - A perfect way for productivity improvement of computer numerical control (CNC) set up in manufacturing company", Journal of Mechanical Engineering Research, vol 5(8), pp. 166-170, Nov. 2013.

[4]. Marri H.B. and Shaikh G.Y.,"The Role of Productivity Improvement Tools and Techniques in the Textile Sector during Manufacturing", Proc of the 2012 International Conference on Industrial Engineering and Operations Management Istanbul, Turkey, 2012.

[5]. Mishra R., "Productivity improvement in Automobile industry by using method study", International Journal of Scientific Engineering and Applied Science, vol. 1, Issue-4, July 2015.

[6]. Shrivastava R.K. and Shridhar K, "Productivity \& Quality Improvement Through Kanban - A Case Study', in Proc of BITCON-2015 Innovations For National Development National Conference, 2015, p. 251.

[7]. Singh M. D., Singh S., Keyur D., Saumil S., Niki P, Harshal P, "Overall Productivity Improvement in Casting Industry by Using Various Industrial Engineering Techniques“, International Journal of Innovative Research in Science, Engineering and Technology, vol. 4, Issue 1, Jan. 2015.
[8]. Verma N., Trivedi P. and Agnihotri V., "Productivity Improvement in Assembly Line of an Automobile Industry", IOSR Journal of Mechanical and Civil Engineering, vol. 12, pp. 01-06, Aug. 2015. 